\title{
Implication of Knowledge Stock on Knowledge Acquisition via E-Learning
}

\author{
Bing Wu \\ School of Economics and Management, Tongji \\ University, Shanghai, China \\ Email: ww_bing@163.com
}

\author{
Chenyan Zhang \\ Logistics Research Center, Shanghai Maritime \\ University, Shanghai, China
}

\begin{abstract}
Knowledge stock as one of the important parts of knowledge interaction has important implication on knowledge acquisition via E-Learning community. Research frameworks are proposed in the following way. Knowledge stock is analyzed in detail way to find characteristics. Then key factors of knowledge acquisition via E-Learning are identified into knowledge acquisition bases, knowledge acquisition performance and knowledge acquisition targets. Mathematic models are constructed for knowledge stock. Afterwards guided by research framework, a specific research design is composed to address the research questions adequately. Computational technique and analysis are used to make simulation experiment, so that unique perspectives on knowledge stock to influence knowledge acquisition via $\mathbf{E}$ Learning community can be provided for strategies of $\mathrm{E}$ Learning.
\end{abstract}

Keywords- Knowledge stock; Knowledge acquisition; Community; E-Learning

\section{INTRODUCTION}

The learning capacity of an enterprise' members determine its organizational competitiveness in this age influenced by a growing knowledge economy. Corporate competitiveness may be determined from the content of E-Learning and social learning groups. In a practical E-Learning scenario, the information and knowledge exchange is more frequent than that in a normal information retrieval case on the Web, because people naturally treat an E-Learning system as more organized information and knowledge base rather than a massive global network. Thus, E-Learning has been regarded as a fast growing research and application area with huge market potential. It may become an essential corporate strategy to connect with the rapid development of knowledge communities surrounding E-Learning while in the process of promoting knowledge management.

In recent years, great attention concentrated on the relationship between the features of network organizations and their behavioral patterns [1-3], including three layers, i.e., knowledge accumulation, knowledge interaction and knowledge diffusion. Meanwhile knowledge stock is one of the important sources for E-Learning knowledge acquisition. These studies probed processes of knowledge acquisition in network organization but focused less attention on the relationship between features of knowledge stock and knowledge acquisition dynamics in network. As a result, based on these ideas and characteristics of knowledge acquisition via E-Learning in community, simulation experiment for implication of knowledge stock on the critical factors is proposed to research characteristics emerged by behavior patterns in knowledge acquisition, so that research results can help to achieve E-Learning targets.

This paper is organized as follows. In section 2, relating literature review is presented. In section 3 the research framework is proposed, and then research design is built in section 4. Finally, our work of this paper is summarized in the last section.

\section{LITERATURE REVIEW}

\section{A. Social network in knowledge community}

Social network in knowledge community is reviewed as the context of this study. Benefits from an efficient knowledge community can bring to an organization environment including: learning curve improvement; quick response and efficient customer satisfaction (QR/ECS); added experience sharing within an organization; a decrease in repetitive work, enhanced communication and innovation; efficient resolution of practical problems; and increased learning capability overall in relevant areas of growth [4].

The whole structural characteristics [5] of the social network, such as network size, network density, network whole, network centrality and network topology, can be used to understand the whole social network structure. While the interpersonal characteristics of the social network, such as strong connection and weak connection, can be applied to explain intimacy or ideal relationship according to the contact frequency.

In social network services oriented enterprise knowledge community, the common goals of social network among individuals or inter-organizations are to construct knowledge interaction relationship. Moreover E-Learning network is determined by the participants, especially continued participants with high activity, so the active participants have more control over knowledge acquisition network via E-Learning community.

\section{B. Knowledge acquisition in the network}

This section summarized the past literatures exploring the trade-off between network size and knowledge acquisition 
to provide the rationale and theoretical supports for the validity of our study.

The recent research mainly concentrates on two aspects of network size. One considers size as a moderator for the relationships between constructs, comparing small and large web-based communities.

Findings highlight that small communities operate differently from larger ones with regard to numerous aspects, and possess specific strengths and weaknesses [6]. The other research streams focused on individuals with larger networks are less emotionally close to each member of their network [7-8]. Consequently, there may be a trade-off between the number of members in the network and the emotional intensity of each relationship in the networksmaller networks tend to contain fewer individuals but at a higher level of emotional closeness than large networks.

Meanwhile the recent research concerned knowledge acquisition in two ways. One is from the perspective of knowledge flow and the structural characteristics of organizations [9-10] (Uzzi \& Gillespie, 2002; Uzzi \& Lancaster, 2003), the results of which indicate that knowledge flow is positively related with the connectedness of organizations [11]. On basis of cognitive psychology and social psychology, the other research branches disclose the relationships of learning, the absorptive capability and effectiveness of knowledge flow [12] (Loasby, 2001).

However, these studies focused less attention on corporations embarking on knowledge community-based ELearning and the relationship between features of macrodynamics of knowledge acquisition in network organization. Following the same logic, we predict that implication of network size on knowledge acquisition via E-Learning varied with network scale. E-Learning network size is determined by the size of the participants, especially continued participants with high activity, and so the active participants have more control over the size of their knowledge acquisition network via E-Learning. Thus, the implication of network size worked on critical factors of knowledge acquisition via E-Learning should be explored.

Network of knowledge acquisition can be shown as there are knowledge suppliers to meet the requirement from knowledge customers. They have different types of knowledge, such as knowledge capacity, knowledge stock and learning schedule.

\section{Research Gaps}

Prior studies exploring SNS, Knowledge acquisition via E-Learning and Knowledge acquisition in the network usually focused on one or more social relationship discussion variables. But little research has examined implication of knowledge stock on knowledge acquisition via E-Learning. Moreover, empirical studies are mainly used to research micro-level behavior in network organization. However it is difficult to accurately collect primary data on the evolution of network organizations and focus on the links of micro-macro behavior in network organization.

To address these gaps, we conduct a virtual experiment approach. Also we employ more sophisticated techniques to analyze the knowledge acquisition via E-Learning so that we can model corporations embarking on knowledge community-based E-Learning in a more nuanced manner. Such an effort is made in order to answer the following research questions: Will knowledge stock influence ELearning targets, performance, bases over time? If it does, how does the effect change differently?

\section{RESEARCH FRAMEWORK}

Based on research questions, research framework can be illustrated as followings. Firstly, critical factors for knowledge acquisition via E-Learning in SNS oriented enterprise knowledge community are classified into bases, targets and performance. Secondly, mathematical models were constructed for constituents of critical factors respectively, and then followed by virtual experiment. In the end, simulation results as feedbacks are analyzed to explore the knowledge stock implication.

\section{A. Knowledge stock}

In each knowledge dimension, knowledge stock of the enterprise is composed of knowledge and skills of all employees [14]. According to individual mental model, knowledge of one people will be deepened and extended through learning driven by stimulating factors, such as environment and events. As a result, new idea and insight will produce during the procedure of knowledge absorption and adjustment. Thus, knowledge stock has close relationship with initial knowledge stock, knowledge demand, E-Learning experience, knowledge value, and knowledge acquisition cost and network size. Accordingly, knowledge stock of the enterprise depends on initial knowledge stock, knowledge gap between knowledge demand and knowledge stock, E-Learning experience, knowledge gains from knowledge value and knowledge acquisition cost, and network size.

\section{B. Critical factors}

Critical factors are essence components for knowledge acquisition via E-Learning in SNS oriented enterprise knowledge community [15]. According to the Professor William Zani of Harvard (1970), critical successful factors can be used to determine the performance of information system, so critical successful factors for knowledge acquisition via E-Learning in SNS oriented enterprise knowledge community can be classified into bases, targets and performance.

\section{Mathematical model}

Knowledge stock of the enterprise at time $t$ KWStock, depends on initial knowledge stock $k$ WStock $k_{o}$, knowledge 
gap $\quad k w$ Demand $d_{-1}-k_{\text {WStock }}$, $_{-1} \quad$ E-Learning experience IExperience $_{t-1}$, knowledge gains $k_{W V a l u e}-k \operatorname{Cost}_{t-1}$ and network size $N$ Size $_{t-1}$ at time $t-1$.

The development of organization's competencies will evolve with time, having the characteristics of path dependent. And organization's competencies acquiring by learning depend on previous E-Learning experience, which has positive implication on knowledge innovation capability of the organization [16]. Thus E-Learning experience has close relationship with knowledge gap, knowledge acquisition gains and network size.

E-Learning experience at time $t$ Experience, depends on initial E-Learning experience Experience, E-Learning experience Experience $e_{-1}$, knowledge gap $k_{\text {WDemand }}-$ kwStock $_{t-1}$, knowledge gains

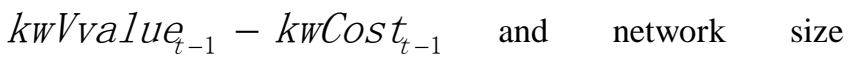
$N S i z e_{t-1}$ at time $t-1$.

Knowledge demand can be divided into exogenous and endogenous knowledge requirements. Exogenous knowledge demands mainly come from market, such as development of new product; knowledge update requirements by employee result endogenous knowledge demands. E-Learning in SNS oriented enterprise knowledge community as a new knowledge service can help the employee with problem solving by refining knowledge from all explicit and tacit information resources, and then employee can customize knowledge according to their own needs, consequently knowledge demand has close relationship with knowledge gap and knowledge acquisition rate. Accordingly knowledge demand of the enterprise at time $t$ KWDemand depends on initial knowledge demand kwDemand , knowledge gap $k_{w D e m a n d}-$ kwStock $_{t-1} \quad$, E-Learning experience Experienc $\varepsilon_{-1}$, and knowledge acquisition rate $k w R a t e_{t-1}$ at time $t-1$.

As life cycle is one of the important characteristics of knowledge, knowledge acquisition value has close relationship with knowledge acquisition rate and knowledge acquisition demand. Accordingly, knowledge value of the enterprise at time $t K W V a l u e_{t}$ depends on initial knowledge acquisition value kwValue , knowledge acquisition value $k W V a l u e_{t-1}$, knowledge gap $k_{\text {WDemand }}-$ kwStock $_{t-1} \quad$, E-Learning experience Experience $e_{-1}$, and knowledge acquisition rate kwRate $_{t-1}$ at time $t-1$.

\section{RESEARCH DESIGN}

Guided by research framework and previous literatures, a specific research design is composed to address the research questions adequately.

In order to enhance understanding of complex behavior of human organization [17], computational techniques and computational analysis can be used. In this aspect, virtual experiment takes many advantages of analyzing organizational phenomena through mathematical models in the following reasons. The virtual experiment provides us unique perspectives on how individuals respond and how emergent patterns will appear in uncertainty and ambiguity [18].

One example of the experiment results are shown as Fig 1 and Fig 2. It can be seen increase of knowledge stock has positive effect on network size till certain threshold, which means E-Learning participation necessitate the rich knowledge stock. Meanwhile the result that knowledge stock has little effect on E-Learning experience shows factors other than knowledge stock have close relationship with E-Learning experience.

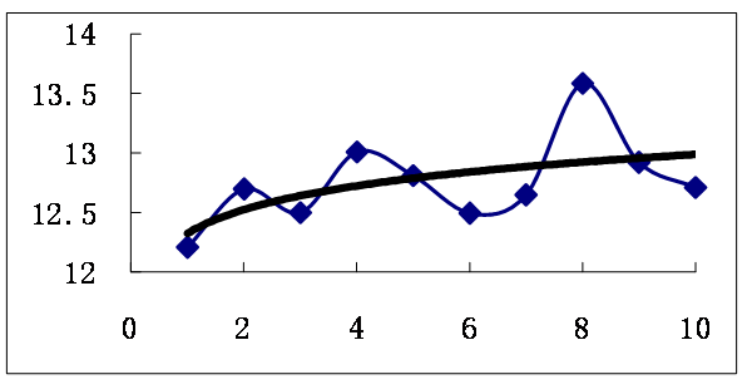

Figure 1. Implication of knowledge stock on network size.

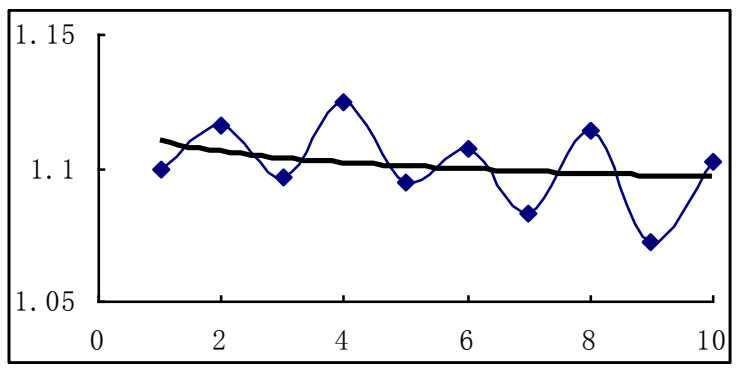

Figure 2. Implication of knowledge stock on E-Learning experience.

\section{CONCLUSIONS}

Our study contributes to additional simulation experiment that knowledge stock can influence critical factors for corporations embarking on knowledge community-based E-Learning. When using knowledge stock to study knowledge acquisition behavior, we try to find that 
knowledge stock worked in different way to critical factors of knowledge acquisition. As most variables of critical factors are changing over time, often new relationship between variables and knowledge stock emerges, and old one disappears.

However in this paper, we just analyzed knowledge stock by simulation experiment and could not thoroughly explain the real factor behind results. More factors in addition to knowledge stock, such as network size, ELearning experience should be combined in synthesized way to study their general implication on the relationship between knowledge community and E-Learning behavior.

\section{ACKNOWLEDGMENT}

This work was supported in part by NSFC under Grant Nos. 71071117.

\section{REFERENCES}

[1] Argote, L., \& Ingram, P. Knowledge transfer: a basis for competitive advantage in firms. Organizational Behavior and Human Decision Processing, vol.82, no., pp., 2000

[2] Argote, L., McEvily, B., \& Regans, R. Managing knowledge in organizations: an integrative framework and review of emerging themes. Management Science, vol.49, no., pp., 2003

[3] Reagans, R., \& McEvily, B. Network structure and knowledge transfer: The effects of cohesion and range. Administrative Science Quarterly, vol.48, no., pp., 2003

[4] Bing Wu, et, al. Experience Effect in E-Learning. Physics Procedia, vol.24, no.Part C, pp., 2012

[5] Patrick Doreian, Norman Contis. Social context, spatial structure and social network structure. Social Networks, vol.34, no.1, pp., 2012

[6] Daniele Scarpi. Does Size Matter? An Examination of Small and Large Web-Based Brand Communities. Journal of Interactive Marketing, vol.24, no., pp., 2010
[7] Pei-Luen Patrick Rau, Qin Gao, Yinan Ding. Relationship between the level of intimacy and lurking in online social network services. Computers in Human Behavior, vol.24, nol., pp., 2008

[8] Ahuja, G. Collaboration networks, structural holes and innovation: a longitudinal study. Administrative Science Quarterly, vol.45, no., pp., 2000

[9] Uzzi, B., \& Gillespie, J. J. Knowledge spillover in corporate financing networks: Embeddedness and the firm' $s$ debt performance. Strategic Management Journal, vol.23, no., 2002

[10] Uzzi, B., \& Lancaster, R. The role of relationships in interfirm knowledge transfer and learning: The case of corporate debt markets. Management Science, vol.49, no., pp., 2003

[11] Fangcheng Tang, Jifeng Mu, Douglas L. MacLachlan. Implication of network size and structure on organizations'knowledge transfer. Expert Systems with Applications, vol.34, no., pp.,2008

[12] Loasby, B. J. Time, knowledge and evolutionary dynamics: why connections matter. Journal of Evolutionary Economics, vol.11, no., pp., 2001

[13] Wu Bing, Liu Zhong-ying. Research on supply chain configuration flexibility based on knowledge coupling. International Conference on Wireless Communications, Networking and Mobile Computing, WiCOM 2007

[14] Andrew N. K. Chen, Yuhchang Hwang, T. S. Raghu. Knowledge Life Cycle, Knowledge Stock, and Knowledge Acquisition. Strategies Decision Sciences, vol.41, no.1, pp., 2010

[15] Ruey-Shun Chen, Chin-Hsiao Hsiang. A study on the critical success factors for corporations embarking on knowledge community-based e-learning. Information Sciences, vol.177, no., pp., 2007

[16] Jocelyn Cranefield and Pak Yoong Embedding personal professional knowledge in a complex online community environment Online Information Review, vol.33, no.2, pp., 2009

[17] Carley, K. M. A comparison of artificial and human organizations. Journal of Economic Behavior and Organization, vol.31, no., pp., 1996

[18] Welfe W. LONG-TERM SIMULATION MODEL FOR A KNOWLEDGE-BASED ECONOMY. ARGUMENTA OECONOMICA, vol.25, no.2, pp., 2010 